\title{
The Drosophila Pkn protein kinase is a Rho/Rac effector target required for dorsal closure during embryogenesis
}

\author{
Yu Lu and Jeffrey Settleman ${ }^{1}$ \\ Massachusetts General Hospital Cancer Center and Harvard Medical School, Charlestown, Massachusetts 02129 USA
}

\begin{abstract}
The PKN family of PKC-related protein kinases constitutes the major Rho GTPase-associated protein kinase activities detected in mammalian tissues. However, the biological functions of these kinases are unknown. We have identified a closely related PKN homolog in Drosophila (Pkn) that binds specifically to GTP-activated Rho1 and Rac1 GTPases through distinct binding sites on Pkn. The interaction of Pkn with either of these GTPases results in increased kinase activity, suggesting that Pkn is a shared Rho/Rac effector target. Characterization of a loss-of-function mutant of Drosophila Pkn revealed that this kinase is required specifically for the epidermal cell shape changes during the morphogenetic process of dorsal closure of the developing embryo. Moreover, Pkn, as well as the Rho1 GTPase, mediate a pathway for cell shape changes in dorsal closure that is independent of the previously reported Rac GTPase-mediated Jun amino (N)-terminal kinase (JNK) cascade that regulates gene expression required for dorsal closure. Thus, it appears that distinct but coordinated Rho- and Rac-mediated signaling pathways regulate the cell shape changes required for dorsal closure and that Pkn provides a GTPase effector function for cell shape changes in vivo, which acts together with a Rac-JNK transcriptional pathway in the morphogenesis of the Drosophila embryo.
\end{abstract}

[Key Words: Pkn; Rho GTPase; Rac GTPase; dorsal closure; signal transduction; Drosophila]

Received December 4, 1998; revised version accepted March 8, 1999.

The Rho family proteins comprise a subgroup of the Ras superfamily of regulatory GTPases that are ubiquitously expressed and highly evolutionarily conserved. The Rho GTPases, which include the Rho, Rac, and Cdc42 proteins, mediate a variety of cellular functions including the regulation of actin reorganization in response to extracellular stimulation. Specifically, activated Rho promotes the assembly of focal adhesions and stress fibers (Ridley and Hall 1992), Rac stimulates the formation of lamellipodia (Ridley et al. 1992), and Cdc42 induces filopodia formation (Nobes and Hall 1995). Thus, these proteins function as critical regulators of cell morphology, motility, and adhesion. In addition to their regulatory roles in remodeling the actin cytoskeleton, Rho GTPases perform crucial functions in a variety of cellular processes, including cell growth and cell cycle progression, intracellular membrane trafficking, cytokinesis, and transcriptional regulation (for review, see Van Aelst and D'Souza-Schorey 1997). However, the organization of GTPase-mediated signaling pathways that control these numerous and diverse biological functions and the nature of signaling specificity are just beginning to be elucidated.

Like all members of the Ras family of small GTPases,

${ }^{1}$ Corresponding author.

E-MAIL Settleman@helix.mgh.harvard.edu; FAX (617) 726-7808. the Rho GTPases function as molecular switches, cycling between inactive GDP-bound forms and active GTP-bound forms. In recent years, numerous potential effector targets of the Rho GTPases have been identified by virtue of their ability to bind to the Rho proteins in a GTP-dependent manner. While some of these effectors exhibit specificity in their ability to bind to a single member of the Rho family of proteins, others can bind to multiple different Rho GTPases. This ability may account, in part, for the observation that distinct members of the Rho family can mediate similar or overlapping cellular functions. Furthermore, different effectors for the same Rho protein can potentially bind to distinct regions of the GTPase, thereby contributing to the specificity of signals to downstream biological processes (Sahai et al. 1998).

Many of the Rho/Rac/Cdc42 effector targets are kinases-predominantly serine/threonine protein kinases. In most cases, these targets appear to be activated by direct binding to the active Rho GTPases and might thereby initiate a signaling cascade that involves selective substrate phosphorylation leading to specific biological responses. For example, GTP-bound Rho activates its effector target, Rho kinase (ROK), which phosphorylates the myosin-binding subunit of myosin phosphatase, leading to smooth muscle contraction and actin stress fiber formation (Kimura et al. 1996). It is also 
possible that these GTPase-kinase interactions serve to regulate the subcellular localization of kinase activity, as appears to be the case for the Ras-Raf interaction (Marais et al. 1995).

Among the putative Rho/Rac effector targets in mammals are the protein kinase $\underline{\mathrm{N}}$ /protein kinase C-related kinase (PKN/PRK) family of serine/threonine kinases (Amano et al. 1996; Watanabe et al. 1996). PKN (also referred to as PRK1) and the closely related protein PRK2 (Quilliam et al. 1996; Vincent and Settleman 1997) together account for the vast majority of Rho-binding autokinase activity detected in most mammalian tissues (Vincent and Settleman 1997). The carboxy-terminal catalytic domains of these kinases are highly homologous to the PKC family kinases, but they possess unique aminoterminal regulatory sequences including three leucine zipper-like repeats shown to be important for the interaction with the Rho GTPase (Flynn et al. 1998). These proteins also interact detectably with the Rac GTPase (Vincent and Settleman 1997; Flynn et al. 1998), suggesting that they may be shared effector targets of the Rho and Rac GTPases. Despite the identification of closely related PKN homologs in several organisms (Mukai et al. 1995; Stapleton et al. 1998), the precise biological function of these putative Rho targets remains unknown.

The ability of the Rho GTPases to regulate cell morphology and motility suggests that these proteins and their associated signaling pathway components are likely to perform functions essential to the normal morphogenesis of developing multicellular organisms. Indeed, recent studies of Drosophila from a number of laboratories have revealed a role for the Rho family proteins in a variety of developmental processes, including gastrulation (Barrett et al. 1997; Hacker and Perrimon 1998), oogenesis (Murphy and Montell 1996), axon outgrowth (Luo et al. 1996; Lamoureux et al. 1997; Zipkin et al. 1997), tissue polarity (Strutt et al. 1997), and dorsal closure (DC; for review, see Noselli 1998). Interestingly, in DC, a role for Drosophila homologs of each of the Rho, Rac, and Cdc42 proteins has recently been identified. DC is a major morphogenetic event that takes place relatively late in embryogenesis, in which epidermal cells stretch along the dorsal-ventral axis such that the two lateral epidermal cell sheets slide over the underlying amnioserosa cells (an epithelial layer) and eventually meet at the dorsal midline to close the dorsal side of the embryo (Martinez-Arias 1993). DC does not require new cell divisions, and appears to depend solely on dramatic cell shape changes within a subset of epidermal cells. These shape changes are initially restricted to two symmetric rows of epidermal cells, known as the leading edge (LE) cells, and are followed by the stretching of the more lateral epidermal cells, ultimately resulting in the meeting of the two rows of LE cells at the dorsal midline.

Three classes of genes have been implicated in DC; namely, the Rho family of GTPases, the c-Jun amino (N)-terminal kinase (JNK) cascade components, including the Decapentaplegic (Dpp) signaling pathway genes, and several membrane-associated proteins (for review, see Noselli 1998). The recently described Drosophila loss-of-function Rho1 mutant is defective for DC, and homozygous mutant embryos exhibit an obvious hole in the dorsal-anterior portion of the larval epidermis (Strutt et al. 1997). Although Rac1 loss-of-function mutants have yet to be reported, overexpression of $\mathrm{Rac}^{\mathrm{N} 17}$, a dominant-negative form of Rac1, in developing Drosophila embryos, results in a DC defect (Harden et al. 1995). Similar results have also been reported for Cdc42 ${ }^{\text {N17 }}$ (Riesgo-Escovar et al. 1996).

It has been reported previously that in mammalian cells, Rac and Cdc42, but not Rho, function as upstream activators of the JNK cascade (Coso et al. 1995; Minden et al. 1995). Interestingly, Drosophila homologs of the mammalian JNK pathway genes, hemipterous (hep; JNKK) (Glise et al. 1995), basket (JNK; Riesgo-Escovar et al. 1996; Sluss et al. 1996), Diun (Glise and Noselli 1997; Hou et al. 1997; Kockel et al. 1997; Riesgo-Escovar and Hafen 1997b), and kayak (Dfos; Riesgo-Escovar and Hafen 1997a; Zeitlinger et al. 1997) are all required for DC. Mutations in any of those genes result in a dorsalopen phenotype very similar to that seen in either the Rho1 mutants or embryos overexpressing dominantnegative Rac1 or Cdc42. Furthermore, disruption of the JNK pathway in hep mutants abolishes the expression of two independent downstream target genes of Djun, $d p p$ and puckered (a MAP kinase phosphatase) (MartinBlanco et al. 1998), which are also required for DC (Glise and Noselli 1997). The hep mutation also blocks an increase in $d p p$ expression in the LE cells induced by expression of activated $\mathrm{Racl}^{\mathrm{V} 12}$ in those cells. These results have led to a model for DC in which Rac1 land possibly Cdc42) signals through the JNK pathway to activate the expression in LE cells of Dpp, a secreted ligand of the TGF- $\beta$ receptor, which in turn relays an instructive signal to initiate stretching of the more lateral epidermal cells (Glise and Noselli 1997; Hou et al. 1997; Kockel et al. 1997; Riesgo-Escovar and Hafen 1997b). The signaling role of Rhol or downstream effector targets of Rhol in this process is unknown.

Here, we report the molecular cloning and biological characterization of a Drosophila homolog of the mammalian PKN family kinases. Drosophila Pkn binds specifically to both Rhol and Racl GTPases in a GTP-dependent manner, and its kinase activity is promoted by both interactions, suggesting that Rhol and Racl GTPases can utilize Pkn as a downstream effector target. A loss-of-function mutation in the Drosophila Pkn gene leads specifically to a DC defect during embryogenesis. However, this Pkn-mediated DC pathway is independent of the Rac-JNK-Dpp pathway, but rather, appears to act coordinately with this pathway to regulate epidermal cell shape changes during morphogenesis of the Drosophila embryo.

\section{Results}

\section{Molecular cloning of Drosophila Pkn}

In an effort to decipher the biological function of PKN and its role in GTPase-mediated signaling, we cloned a 
Drosophila PKN homolog, Pkn, using degenerate oligonucleotide-mediated PCR. The predicted Drosophila Pkn protein sequence is closely related to both human PKN and PRK2 (60\% overall identity to both) and has all of the conserved features found in other PKN family members (Fig. 1A), including the amino-terminal negative regulatory pseudosubstrate motif (Kitagawa et al. 1996), the three leucine zipper repeats (HR1a, HR1b, and HR1c) that mediate GTPase binding (Watanabe et al. 1996; Flynn et al. 1998), a central conserved region of unknown function found in the PKC- $\epsilon$ and PKC- $\eta$ kinases (Palmer et al. 1995), and the carboxyl-terminal PKC-like kinase domain (Fig. 1B). Recently, a partial cDNA sequence was also reported that encodes what appears to be the kinase domain of the same Drosophila Pkn gene (Ueno et al. 1997).

The expression pattern of the Drosophila Pkn gene is highly dynamic during embryogenesis (Fig. 1C). An in situ hybridization analysis of wild-type embryos revealed that Pkn mRNA is abundant at the blastodermal stage, suggesting that it is maternally loaded. At stage 13 , when DC is normally initiated, the most prominent expression is seen in the dorsal LE cells and in two pairs of discontinuous stripes on the epidermis of each segment. However, the expression becomes more restricted in later stages and can only be detected in the anterior and posterior spiracles, the pharynx, and the mouth tip at stage 16 .

\section{Drosophila Pkn binds to activated Rho1 and Rac1 GTPases}

Previous biochemical studies of the human PKN family members, PKN and PRK2, revealed that these proteins can bind directly to the Rho and Rac GTPases in vitro. Moreover, the kinase activity of the PKN/PRK2 proteins is activated by severalfold upon interaction with activated forms of these GTPases. Therefore, we examined potential protein interactions between Drosophila Pkn and several of the Rho family GTPases. For this analysis, an amino-terminally epitope-tagged form of Drosophila Pkn was expressed in transfected BOSC cells, and cell lysates were subjected to binding assays with GST fusions of Drosophila Rho1, Rac1, Rac2, and Cdc42. GTPase-associated Pkn was then detected by immuno-
Figure 1. Predicted protein sequence and expression pattern of Drosophila Pkn. (A) Conserved motifs and domains of the Drosophila Pkn protein and related human PKN family kinases. Homology is displayed as percent identical/similar for each compared domain. (PS) Pseudosubstrate; (LZ) leucine zipper; (RBD) Rho-binding domain; (PKC) PKC- $\epsilon$ and PKC- $\eta$ kinase homology. (B) Alignment of amino acid sequences of the domains conserved between Pkn and its human homologs. Identical amino acids are shaded black. $(C)$ Expression pattern of $P k n$ determined by RNA in situ hybridization. Embryos at the indicated developmental stages were incubated with a digoxigenin-labeled antisense RNA probe corresponding to a $3-\mathrm{kb} P \mathrm{kn}$ cDNA encoding the kinase domain and the 3 '-untranslated region. A stage 5 control embryo was hybridized with the corresponding sense RNA, revealing the apparent maternal loading of $P k n$ mRNA. Arrowheads in the stage 13 embryo indicate enriched Pkn expression in the LE cells.
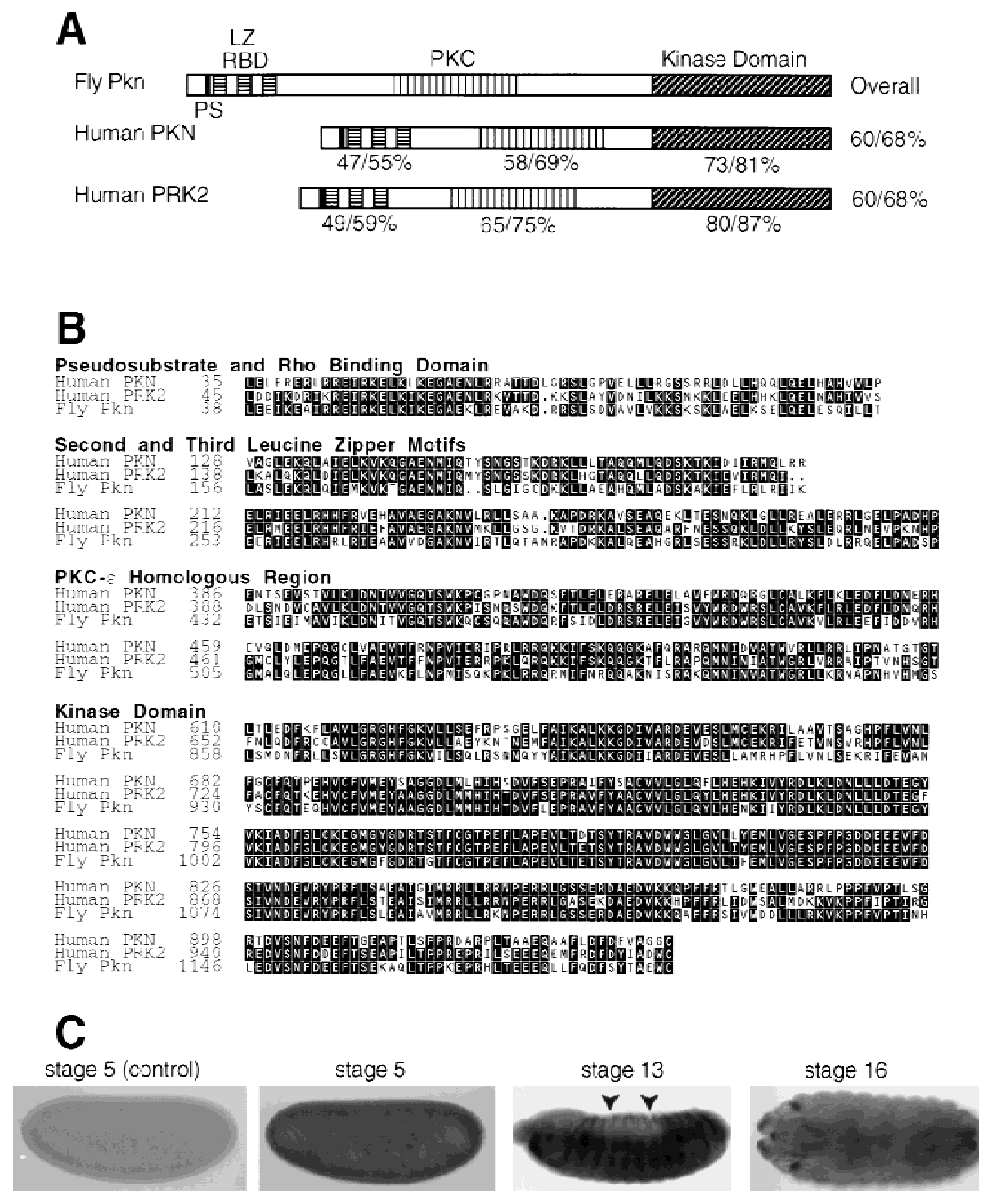
blotting of the epitope tag. As shown, Pkn associates specifically with Rho1, Rac1, and Rac2, but not detectably with Cdc42 or GST alone (Fig. 2A). In addition, the observed binding is strictly dependent on the activated GTP $\gamma$ S-bound form of Rho and Rac.

By performing similar binding assays with the isolated amino-terminal and carboxy-terminal regions of Pkn, we determined that both Rhol and Racl bind Pkn through the amino-terminal region of the protein (Fig. 2B). Significantly, it appears that Rhol and Racl interact with $\mathrm{Pkn}$ through distinct binding sites. This interaction is indicated by the fact that Rho1, but not Rac1, exhibits a highly preferential interaction with an apparent breakdown product of $\mathrm{Pkn}$ which, on the basis of its gel mobility, is expected to lack the kinase domain but maintain the amino-terminal putative Rho/Rac-binding sites and pseudosubstrate domain (Fig. 2A). To confirm this expectation, we generated a mutated form of $\mathrm{Pkn}$ in which a highly conserved amino acid in the HRla domain (glycine 58) was substituted with alanine, and tested this form of Pkn for Rhol and Racl binding. As shown (Fig. 2C), the mutated form of Pkn binds Rhol well, but does not interact detectably with Racl, suggesting that Rho and Rac may bind Pkn through different HR1 domains.

\section{Pkn kinase activity is stimulated by the Rho and Rac GTPases}

We observed that the interaction of Pkn with Rho and Rac proteins requires the activated, GTP-bound forms of these GTPases, suggesting that Pkn serves as a downstream effector target of Rhol and Racl. To confirm this possibility, we examined the ability of activated Rhol and Racl proteins to stimulate the kinase activity of Pkn. First, we determined that Pkn, when immunoprecipitated from transfected BOSC cells, exhibits a readily detectable autokinase activity (Fig. 2D). Thus, Pkn is somewhat active in the absence of GTPase interaction. Then, we compared the level of autokinase activity of equivalent amounts of Pkn isolated either by immunoprecipitation from cell lysates or captured from lysates via interaction with activated, GTP $\gamma$ S-loaded forms of GST-Rhol or GST-Rac1. As shown, Pkn protein in association with activated Rhol or Racl exhibits approximately four- to fivefold more autokinase activity than free Pkn (Fig. 2E). This degree of activation is similar to that reported previously for the human PKN and PRK2 proteins associated with the RhoA GTPase and supports the conclusion that Drosophila Pkn functions as an effector target of both Rho and Rac GTPases.
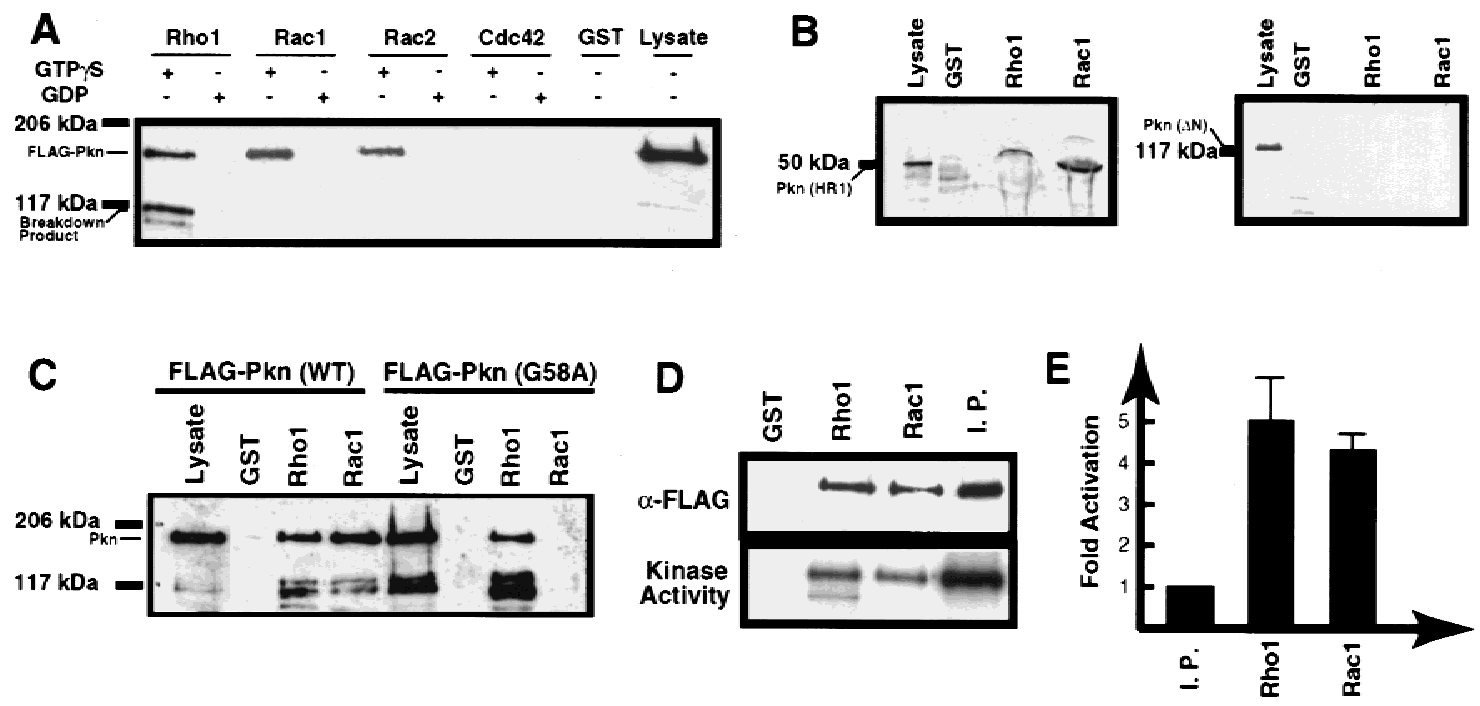

Figure 2. Pkn is an effector target of Rho and Rac GTPases. (A) Lysates of BOSC cells transfected with Flag-tagged Pkn plasmid were incubated with GST-fusion proteins on sepharose beads (preloaded with either GDP or GTP $\gamma$ S). Proteins bound to the beads were analyzed by anti-Flag immunoblotting. (Lysate) $3 \%$ of the input for each binding assay. (B) Similar binding assays with either the Pkn amino-terminal HR1 domain (left), or the Pkn carboxy-terminal region lacking the HR1 domain (right) were carried out as described in $A$. Both proteins are Flag tagged. The distorted mobility of Pkn HR1 bands in $B$ (left) is due to the comigration of large amounts of the GST-fusion proteins. $(C)$ Binding assays with either the wild-type Pkn protein or the Pkn mutant with the G58A substitution were carried out as described in $A$. Both Pkn proteins are Flag tagged, and both GST-Rhol and GST-Rac1 were preloaded with GTP $\gamma$ S. (D) Lysates from Pkn-transfected cells were incubated either with GST-fusion proteins as described in Materials and Methods, or anti-Flag antibody and protein-G beads (immunoprecipitation) before the washed samples were split into two halves. One half was analyzed by SDS-PAGE and anti-Flag immunoblot. The other was subjected to an autokinase assay followed by SDS-PAGE and autoradiography. The amount of Flag-Pkn in the immunoblot corresponds to 1/16 of the total immunoprecipitated protein, while the radioactive band in the autokinase assay corresponds to $1 / 2$ of the total immunoprecipitated protein. $(E)$ Pkn kinase activation upon Rho1 or Rac1 binding was quantitated by autoradiography, and the results from three independent experiments were averaged. Error bars represent standard errors of the mean (S.E.M.). 


\section{Pkn mutant embryos are defective for DC}

The Pkn gene was mapped to the cytogenetic region 45C. Several previously described P-element insertions map to this same region, and we found that one of these is inserted in an intron whose $5^{\prime}$ end is located 21 bp downstream of the putative ATG start codon of the Pkn-coding sequence within the genomic DNA (Fig. 3A). Flies harboring this P-element insertion, when made homozygous, exhibit a multi-phasic lethal phenotype in which flies die from late embryonal through pupal stages, but no adult homozygous mutants emerge. Although homozygous mutant embryos do not exhibit obvious developmental defects prior to stage $13, \sim 10 \%$ of them die as embryos with an obvious hole in the anterior region of the dorsal epidermis (Fig. 3E). This dorsal-open phenotype closely resembles the DC defects observed previously with loss of function of the Rho1 gene (Fig. 3C) and several components of the Rac-mediated JNK cascade.

Two independent lines of evidence indicate that the observed lethality and dorsal-open phenotypes are caused by disruption of the Pkn gene by the P-element insertion. First, transposase-mediated precise excision of the P-element yields fully viable and fertile adults, and no dorsal-open embryos were observed among $>450$ relevant progeny examined (Table 1). Second, expression of a $P k n$ cDNA encoding the full-length Pkn protein under the control of a heat-shock promoter in transgenic flies can rescue the viability and fertility of P-element-harboring flies and significantly reduces the number of dorsal-open embryos (Table 1).

To examine the requirement for maternally loaded $P k n$ mRNA, germ-line clone (GLC) mutants of $P k n$ were
Table 1. Embryos with dorsal closure defects

\begin{tabular}{lcr}
\hline Genotype & $\begin{array}{c}\text { DC } \\
\text { embryos } \\
(\%)\end{array}$ & $\begin{array}{c}\text { Total } \\
\text { no. } \\
(n)\end{array}$ \\
\hline$P k n^{P} / P k n^{P}$ & $9.6 \pm 1.6$ & 1014 \\
$P k n^{E[P]}$ (precise excision allele) & 0 & 451 \\
$G L C / P k n^{P}$ & $55.2 \pm 0.4$ & 1066 \\
$G L C / D f(45 C)$ & $48.2 \pm 2.4$ & 617 \\
$G L C / P k n^{P} ; P[h s-P k n] /+$ (heat shock) & $14.6 \pm 3.2$ & 1112 \\
$G L C / P k n^{P} b s k^{1}$ & $76.2 \pm 5.6$ & 2998 \\
$G L C / P k n^{P} R^{1}{ }^{72 R}$ & $68.2 \pm 1.2$ & 2613 \\
\hline
\end{tabular}

Crosses were set to obtain embryos of the indicated genotypes. Except for the Pkn heat shock rescue cross (line 5), all crosses were maintained overnight at $25^{\circ} \mathrm{C}$ to collect 0 - to $18 \mathrm{hr}$ embryos, and the percentage of embryos with dorsal closure defects was determined as described. For the heat shock rescue experiment, a 0- to 2-hr collection of embryos was allowed to age for 5 more hours before a $30-\mathrm{min}$ heat shock at $37^{\circ} \mathrm{C}$ was administered. Embryos were then treated as those of other groups. The percentages of embryos with DC defects as compared to the expected total number of mutants (or the total number of all fertilized embryos in the case of $\left.P k n^{E[P]}\right)$ are listed. Results are shown as the means \pm S.D. of several experiments, and $n$ is the total number of genotypically relevant progeny examined.

generated and $\sim 50 \%$ of the mutant embryos derived from these clones were found to display the same DC defect (Fig. 3F). Phenotypic analysis of these embryos with various histological markers revealed that they are correctly patterned and do not exhibit any detectable defects of the central or peripheral nervous system or the somatic musculature (data not shown), suggesting that Pkn is not
Figure 3. A P-element insertion in the $P k n$ gene causes a DC defect. (A) Genomic map of the $5^{\prime}$ end of the Pkn locus. The two exons are displayed as open boxes, and the intron between them is displayed as a discontinuous line. The size of the intron is based on genomic Southern blots and is estimated to be minimally $10 \mathrm{~kb}$. The insertion point of the P-element is based on a comparison of DNA sequences obtained from the recovered genomic DNA that flanks the P-element and the corresponding wild-type genomic region. Intron-exon boundaries were determined by comparison of $P k n$ cDNA and genomic DNA sequences. (PZ) The lacZ-containing P element; (ATG) the predicted start codon of the Pkn cDNA. Cuticle preparations of $(B)$ wild type $(W T)$ and various DC mutants, including $(C) R h o 1^{72 O}$ (a null allele), (D) $b s k^{1}$ (a strong DINK allele), (E) $\mathrm{Pkn}^{P}$ (a null allele), (F) $G L C / P \mathrm{kn}^{P}$, and $(G) G L C / D f(45 C)$ (deficiency uncovering the $P k n$ gene), reveal that in all cases, except wild type, a dorsal-open phenotype is apparent. mRNA in situ hybridization with a $\mathrm{Pkn}$ antisense probe revealed that Pkn mRNA in the GLC mutant embryo $(J)$ is undetectable as compared with the heavily maternally loaded message in a wild-type embryo $(H)$, indicating that the $P \mathrm{kn}^{P}$ allele is a null allele. (I) Sense probe control of a wild-type embryo.

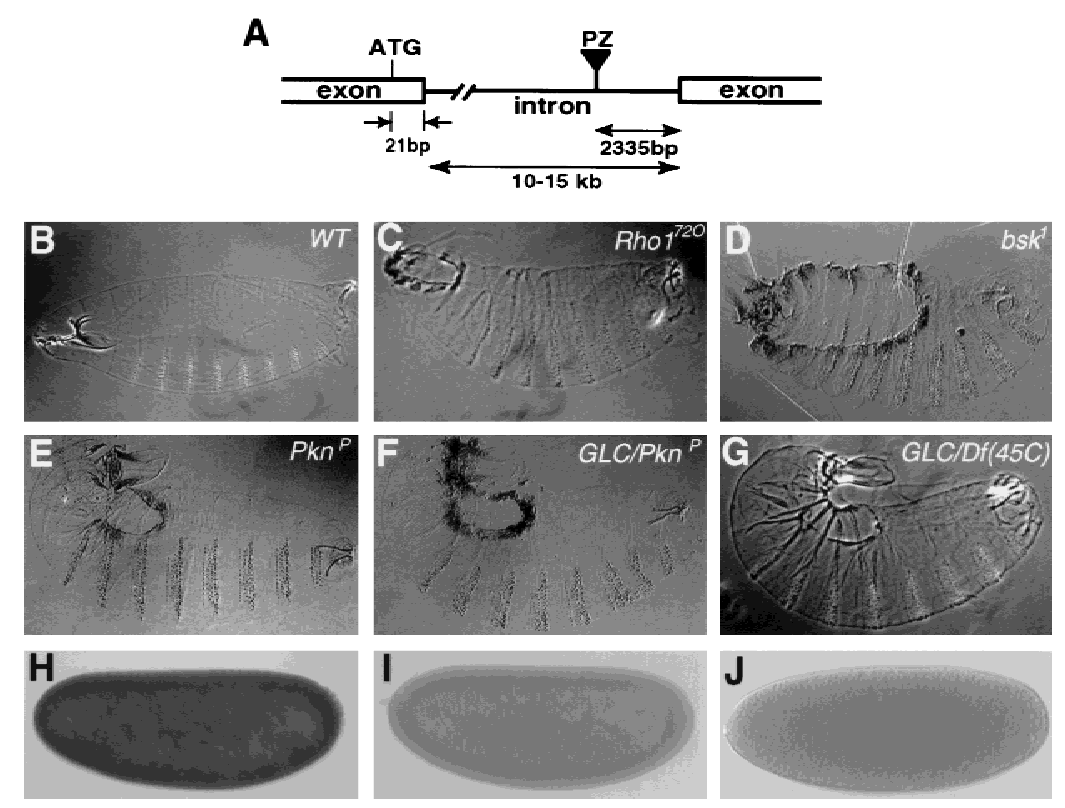


required prior to DC. An identical dorsal-open phenotype, with similar penetrance, was observed when GLC females were crossed to males harboring a chromosomal deficiency uncovering the 45A-D region, which contains Pkn (Fig. 3G; Table 1). In addition, whole-mount embryo in situ hybridization with a $P k n$ probe revealed that the mRNA signal in the GLC-derived embryos was not detectable when compared to that of wild-type embryos (Fig. 3H-J). Finally, in generating the precise P-element excisions described above, we isolated $>30$ independent deletion alleles (imprecise excisions), including a few that had several kilobases of flanking DNA deleted (but not the entire gene). All of these alleles, when made homozygous, exhibit the same DC defect, with similar penetrance, as the original P-insertion allele, and none is more severe. Together, these results suggest that the Pelement mutant allele of $P k n$ is a genetic null allele and that Pkn normally plays a specific role in DC during Drosophila embryogenesis.

\section{Pkn is not required for the Rac-INK pathway in DC}

According to the current working model of DC, the Rac1 and Cdc42 GTPases activate the downstream JNK cascade kinases to induce the expression of several genes in the LE cells, including $d p p$ (Glise and Noselli 1997; Hou et al. 1997; Kockel et al. 1997; Riesgo-Escovar and Hafen 1997b). Thus, $d p p$ mRNA expression in the LE cells is a convenient assay of activation of the JNK cascade in vivo. Because Pkn functions biochemically as a Racl effector target, and mutations in $P k n$ cause a DC defect similar to that seen with JNK pathway mutants, we wanted to determine whether Pkn is required for the previously established Rac-JNK-Dpp pathway. Therefore, we examined the expression of $d p p$ mRNA in $P k n$ mutant embryos. As reported previously, we confirmed that mutations in the JNK cascade gene hep (Glise et al. 1995 ) result in embryos that fail to express detectable levels of $d p p$ mRNA in the LE cells (Fig. 4, cf. A with C, and $\mathrm{B}$ with D). In contrast to the loss of $d p p$ expression seen in hep mutant embryos, expression of $d p p$ in the LE cells of Pkn mutants is not detectably affected (Fig. 4, cf. $\mathrm{E}$ and $\mathrm{F}$ with $\mathrm{A}$ and $\mathrm{B}$ ), indicating that $\mathrm{Pkn}$ is not required for the previously reported Rac-JNK-Dpp pathway. This conclusion was also verified by examination of the expression of $\beta$-galactosidase from a puckered-lac $Z$ enhancer trap, which has been shown previously to be eliminated in a hep mutant background /Glise et al. 1995). As shown, Pkn mutant embryos that exhibit an obvious dorsal-open phenotype retain normal levels of puckered-lacZ expression (Fig. 4O), confirming that the Rac-JNK pathway leading to transcriptional activation is not detectably affected by the absence of Pkn.

Next, we examined the shapes of epidermal cells of $P k n$ mutant embryos and found that all epidermal cells adopt an unstretched polygonal shape (Fig. 4L) following an initial apparently normal LE cell stretching (Fig. 4K), similar to that seen in the JNK pathway mutants, such as hep (Fig. 4I,J). Thus, it appears that while both Rac-JNKand Pkn-mediated signals are required for the stretching of epidermal cells required for DC, they are associated with distinct pathways. Because the expression of Pkn mRNA is enriched specifically in the LE cells prior to DC, we also tested the possibility that Pkn expression is

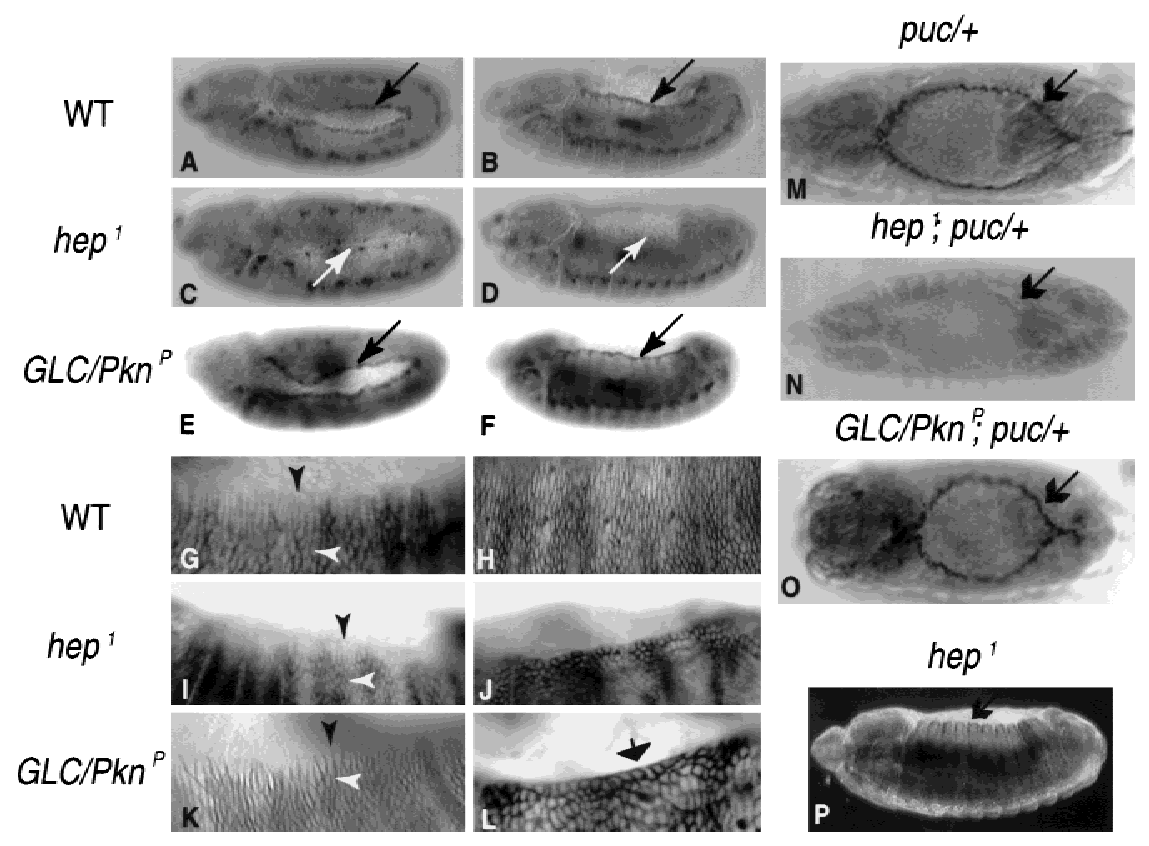

Figure 4. Pkn functions in a Dpp-independent signaling pathway for DC. $(A-F)$ Whole-mount $d p p$ in situ hybridizations of stage 11 (left) and stage 13 embryos (center), in wild-type embryos $(A, B)$, hep ${ }^{1}$ mutants $(C, D)$, and Pkn GLC mutants $(E, F)$. (Black arrows) LE cells where normal levels of $d p p$ expression were observed; (white arrows) LE cells in the hep ${ }^{1} \mathrm{mu}$ tants in which $d p p$ expression is diminished $(C$, stage 11$)$ or absent $(D$, stage 13$)$. $(G-L)$ Anti-fas III staining of the lateral epithelia of stage $13(G, I, K)$ and stage 16 $(H, J, L)$ embryos during DC, in wild-type embryos $(G, H)$, hep ${ }^{1}$ mutants $(I, J)$, and GLC $/ P k n^{P}$ mutants $(K, L)$. (Black arrowheads) Correctly stretched LE cells; (white arrowheads) polygonal shaped unstretched lateral cells in stage 13 embryos. The black arrow in $L$ shows incorrectly localized fas-III signal in the dorsalmost side of the LE cells in homozygous Pkn mutant embryos. $(M-O)$ Anti- $\beta$-galactosidase staining of the puckered-lacZ enhancer trap line embryos in wild-type $(M)$, hep ${ }^{1}$ $(N)$, and Pkn GLC mutant $(O)$ backgrounds. (Black double arrows) LE of various embryos where $\beta$-galactosidase staining is seen normally in the wild-type background. $(P)$ mRNA in situ hybridization with a $P k n$ probe revealed that $P k n$ expression is unaffected in the hep ${ }^{1}$ mutant background, indicating that $P k n$ expression is not under the transcriptional control of the JNK pathway. (Black arrow) Pkn signal in the LE cells. 
regulated by the JNK pathway. However, we found that Pkn expression is unaffected in hep mutant embryos (Fig. 4P).

Accumulating evidence suggests that the Rac1 GTPase, as well as some of the JNK pathway components, performs a function in the LE cells that may be distinct from the regulation of gene expression, but is necessary for the stretching of the LE cells (Riesgo-Escovar and Hafen 1997b). Because we observed that Pkn is a biochemical effector of the Rac1 GTPase that mediates $\mathrm{DC}$, but is not required for $d p p$ or puckered gene expression, we tested the possibility that the Pkn mutant interacts genetically with the JNK pathway component, basket. We found that removal of one copy of the basket gene from a $P k n$ mutant GLC background significantly increases the frequency of dorsal-open embryos (from $55 \%$ to $76 \%$; Table 1 ), suggesting that both Pkn and JNK activities converge at some point to affect a related aspect of the DC process.

The Rho1 GTPase is required in the LE cells for the cell shape changes during DC

The Rhol GTPase has also been implicated in DC (Strutt et al. 1997). Null alleles of Rho1 exhibit a DC defect that closely resembles that seen in Pkn mutants (Fig. 3C) although the relevant Rhol-mediated pathway in this process has not been established. Because the cell shape changes in the LE cells appear to initiate the DC process, and Pkn expression is enriched in the LE cells just prior to DC, we wanted to explore the possibility that a Rho1Pkn signal mediates shape changes in those cells. First, we examined the requirement for Rhol activity specifically in the LE cells. For this analysis, we took advantage of the GAL4-UAS system (Brand and Perrimon 1993) to selectively express a dominant-negative form of Rho1 (Rho1 ${ }^{N 19}$; Barrett et al. 1997) in the LE cells (Glise and Noselli 1997) of wild-type embryos. More than $60 \%$ of these embryos display a dorsal-open phenotype very similar to that seen in the Rho1, $P k n$, and JNK pathway mutants (Fig. 5A). Similar to Rho1 (not shown) and Pkn mutants, but not to a hep mutant, embryos expressing Rho1 $^{\mathrm{N} 19}$ in the LE cells exhibit normal levels of $d p p$ mRNA expression in the LE cells (Fig. 5B). Moreover, all of the epidermal cells in these embryos ultimately adopt an unstretched polygonal shape following a normal initial LE cell stretching at early stage 13 (Fig. 5C). This result demonstrates clearly that expression of the dominant-negative Rhol in the LE cells does not cause a dorsal-open phenotype by nonspecifically blocking the RacJNK-Dpp pathway and suggests that a Rhol-mediated second instructive signal is generated in the LE cells, which together with Dpp, is required for the stretching of the more lateral-ventral cells.

As described above, we observed that Pkn mutant embryos as well as embryos expressing Rho1 ${ }^{\mathrm{N} 19}$ in the LE cells exhibit a DC defect despite the absence of a detectable reduction in $d p p$ expression in the LE cells. Taken together with the observations that $\mathrm{Pkn}$ expression is enriched in the LE cells prior to DC, and Pkn appears to
A
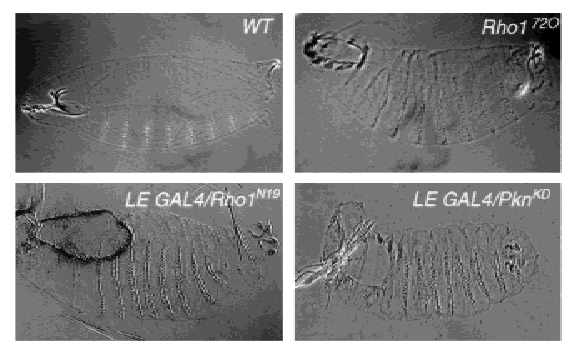

B

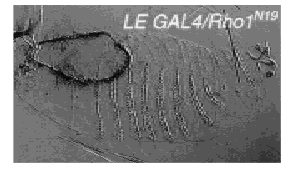

Stage 11

Stage 13
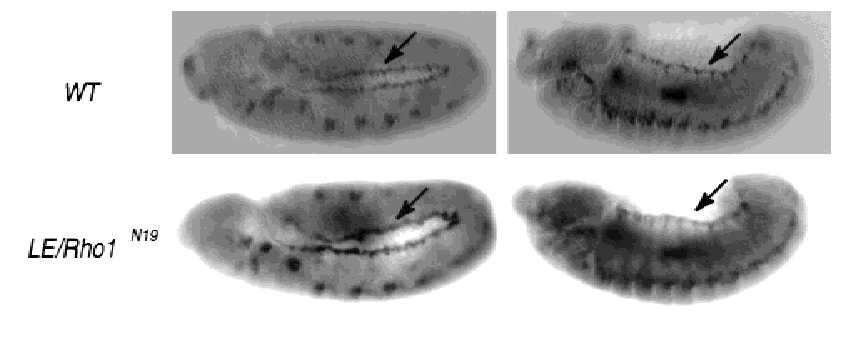

C Stage 13
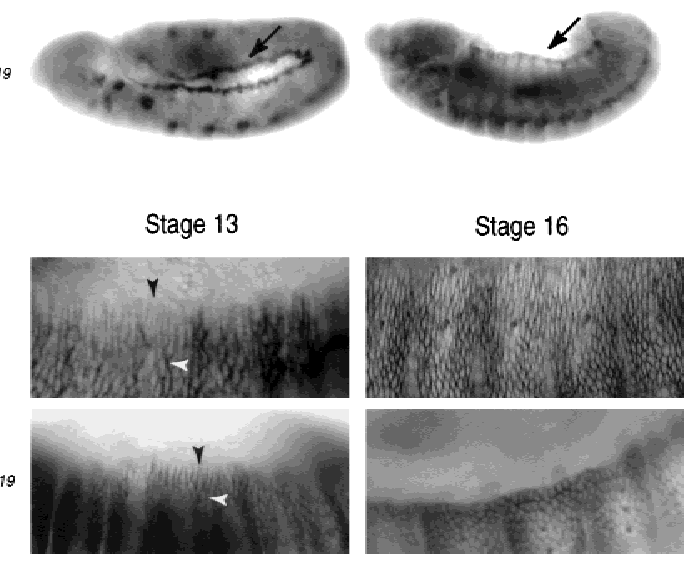

Figure 5. Rhol also mediates a Dpp-independent DC signal in the LE cells. (A) Cuticle preparations of wild-type (WT; same as Fig. 3B), Rho1 ${ }^{72 O}$ (a null allele; same as Fig. 3C), LE GAL4/ Rho1 ${ }^{N 19}$, and LE GAL4/Pkn ${ }^{K D}$ embryos. (B) dpp mRNA in situ hybridization of wild-type and LE GAL4/Rho1 $1^{N 19}$ (LE/Rho1 ${ }^{N 19}$ ) embryos. Normal dpp expression is observed in all stage 11 (left) and stage 13 (right) mutant embryos. (C) Anti-fas III immunostaining of wild-type (same as Fig. 4G, H) and LE GAL4/ $R_{h o 1^{N 19}}\left(L E / R_{h o 1^{N 19}}\right)$ embryos. Note that in both wild-type and mutant stage 13 embryos (left), LE cell stretching is correctly initiated (black arrowheads) whereas lateral cells remain unstretched (white arrowheads), just like those seen in the hep ${ }^{1}$ mutant embryos (see Fig. 4I). However, all epidermal cells of the $h e p^{1}$ and $L E / R h o 1^{N 19}$ embryos eventually adopt the unstretched polygonal shape.

function biochemically as a Rhol effector, these results are consistent with a role for a Rhol-Pkn signal that contributes to the stretching of the LE cells. To establish a specific requirement for Pkn in the LE cells, a transgenic line was established in which a putative dominantnegative form of Pkn (kinase deficient) is expressed under the control of the UAS element. By crossing this line to a line harboring the $L E-G A L 4$ driver, it was determined that a small percentage of embryos exhibit a DC defect that is indistinguishable from that seen in $P k n$ or Rho1 loss-of-function mutants (Fig. 5A). We also examined a potential genetic interaction between Rho1 and $P k n$. In this analysis, we found that removal of one copy 
of the Rho1 gene (a null allele) from the $P k n$ mutant GLC background results in an increase in the frequency of dorsal-open embryos from $55 \%$ to $68 \%$ (Table 1 ). The fact that a reduction of Rhol activity enhances the frequency of DC defects observed in a Pkn-null background suggests that Rhol most likely interacts with at least one additional downstream target that is also required for DC. Consistent with this hypothesis, it was observed that heat shock-induced $P k n$ expression is not sufficient to rescue the Rho1 mutant DC defect (data not shown).

\section{Discussion}

Drosophila Pkn is a shared effector target of Rho and Rac GTPases

We have identified a closely related homolog of the mammalian PKN family of serine/threonine kinases in Drosophila. The structural and biochemical properties of Drosophila Pkn appear to have been well conserved. Previous studies of the human PKN/PRK1 protein indicated that PKN binds specifically to the activated Rho GTPase, although we have also observed a weak, but reproducible, interaction between human PKN and the activated Rac GTPase (Vincent and Settleman 1997). Human PRK2, on the other hand, was found to bind to the RhoA GTPase in a nucleotide-independent manner and to Rac in a strictly GTP-dependent manner (Vincent and Settleman 1997). Moreover, each of these interactions results in an increase in the catalytic activity of the associated kinase. Thus, these proteins may mediate distinct signals via the Rho/Rac GTPases and may perform distinct cellular functions.

Significantly, the Drosophila Pkn protein exhibits approximately equivalent GTP-dependent binding to both Rho and Rac GTPases, consistent with a role for Pkn as an effector target of both GTPases. Although both GTPases interact with the amino-terminal HR1-containing region of $\mathrm{Pkn}$, it is clear that Rhol exhibits a strong binding preference for a kinase-deleted form of $\mathrm{Pkn}$. Most likely, the full-length Pkn protein, but not the truncated form, can assume a conformation in which the carboxy-terminal kinase domain folds back to interact with the amino-terminal pseudosubstrate domain, thereby influencing interactions with the neighboring HR1 GTPase-binding motifs, as demonstrated previously for human PKN (Kitagawa et al. 1996). Thus, the interactions between Drosophila Pkn and Rhol and Racl may be mediated by distinct HR1 repeats in Pkn. Possibly, the distinct complexes of Pkn with either Rhol or Racl result in different subcellular localizations of the protein or different substrate specificities of the GTPasebound kinase. Alternatively, it is possible that Pkn function is sensitive to the simultaneous interaction with Rho and Rac proteins, a scenario in which Pkn may serve to integrate Rho- and Rac-mediated signals. However, we did not observe a synergistic effect of activated Rhol and Racl proteins on Pkn kinase activity when all three proteins were co-incubated (Y. Lu and J. Settleman, unpubl.).
Pkn mediates specific developmental functions downstream of the Rho/Rac GTPases

Currently, little is known regarding the biological role of the mammalian PKN family proteins. Expression of a dominant-negative (kinase-deficient) form of human PRK2 in microinjected fibroblasts results in the disruption of actin stress fibers, suggesting a normal role for PRK2 in regulating Rho-mediated actin reorganization (Vincent and Settleman 1997). Both human PKN and PRK2 undergo partial caspase-mediated proteolysis during apoptosis (Cryns et al. 1997; Takahashi et al. 1998), suggesting a potential role for these kinases in the morphological changes in cells during programmed cell death. Significantly, both Rho and Rac GTPases have been implicated previously in apoptosis (Henning et al. 1997; Lores et al. 1997). A closely related homolog of PRK2 in starfish is highly expressed and specifically phosphorylated in oocytes during meiotic maturation, suggesting a possible role in that process (Stapleton et al. 1998). Human PKN, which is highly expressed in brain, has been found to be enriched in the neurofibrillary tangles associated with Alzheimer's disease and can phosphorylate the Tau protein (Kawamata et al. 1998) as well as the Neurofilament L protein (Mukai et al. 1996), suggesting a potential role for PKN in neuronal degeneration. Despite these observations, the precise biological function of these prominent Rho/Rac effector targets remains unclear.

The results described here provide evidence for a biological function for this putative Rho/Rac-effector target in embryonic development and indicate a specific role for Drosophila Pkn in regulating cell shape changes required for tissue morphogenesis. Previous studies revealed a role for the Drosophila Rhol GTPase in several developmental processes, including gastrulation, establishment of tissue polarity, and DC (for review, see Noselli 1998). However, we find that $\mathrm{Pkn}$ is required only for DC, indicating that $\mathrm{Pkn}$ is not required for all Rhol-mediated activities related to morphogenesis. We have been unable to find evidence for the existence of additional Pkn-related family members in Drosophila by low stringency DNA hybridization methods (Y. Lu and J. Settleman, unpubl.). Thus, it seems likely that additional Rho-associated downstream effector targets mediate the function of Rho in these other developmental processes. Possibly, the ability of Pkn to serve as a target of both activated Rho and Rac GTPases accounts for a specialized role for this protein in DC, which appears to require both Rho- and Rac-mediated signaling pathways. Significantly, gastrulation, a morphogenetic process that is also largely dependent on cell shape changes, requires Rhol but not Rac1 GTPase activity (Barrett et al. 1997) and is unaffected by the absence of Pkn.

The fact that homozygous zygotic $P k n$ mutants that undergo normal DC ultimately die during larval development suggests that Pkn may mediate additional functions of Rho/Rac signaling that are utilized in post-embryonic development. However, we found no obvious developmental defects in somatic homozygous Pkn 
mutant clones in the adult eye, and the loss-of-function $P k n$ mutant does not suppress developmental defects associated with overexpression of Rhol or Racl in the developing fly eye (Y. Lu and J. Settleman, unpubl.). Together with the observation that these GTPases appear to play a role in establishing normal ommatidial polarity (Strutt et al. 1997), these results suggest that it is unlikely that Pkn is mediating the tissue polarity functions of Rho and Rac in eye development. However, we cannot exclude a role for $\mathrm{Pkn}$ in additional morphogenetic processes that take place during larval development.

Rho1 mediates a Dpp-independent instructive signal for $D C$

Although the precise role of $\mathrm{Pkn}$ in DC is not clear, for the following reasons, it appears likely that Pkn is transducing a Rho-dependent signal in the LE cells: (1) Pkn expression is enriched in the LE cells of stage $13 \mathrm{em}$ bryos; (2) the activated Rhol GTPase binds to and activates the Pkn kinase in vitro; (3) loss-of-function Rho1 and Pkn mutants exhibit a very similar dorsal-open phenotype that is associated with a defect in stretching of the LE cells; (4) in both Rho1 and Pkn mutant embryos, expression of $d p p$ mRNA in the LE cells is apparently normal; and (5) expression of the Rho1 ${ }^{\mathrm{N} 19}$ and the $\mathrm{Pkn}^{\mathrm{KD}}$ mutants specifically in the LE cells (where Pkn expression is highly enriched just prior to DC) results in dorsalopen phenotypes that are indistinguishable from the $P k n$ mutant phenotype.

The fact that expression of Rho1 ${ }^{\mathrm{N} 19}$ specifically in the LE cells leads to a cell nonautonomous stretching defect in the more lateral epidermal cells (despite normal $d p p$ expression in the LE cells), suggests that Rhol mediates a second, Dpp-independent, instructive signal (Fig. 6). Possibly, this signal is also mediated by a Rhol-Pkn interaction. However, the finding that removal of one copy of Rho1 from a Pkn mutant GLC background (a genetic null) increases the frequency of dorsal-open embryos suggests that Rhol is probably performing an additional, Pkn-independent, function in DC. In support of this hypothesis, we found that the heat shock-Pkn transgenic construct is unable to rescue the DC defect in Rho1 mutant embryos (Y. Lu and J. Settleman, unpubl.). Thus far, the Rho effector target that mediates the ability of Rho to regulate gene expression via activation of the serum response factor, a known downstream target of Rho activation in mammalian cells (Hill et al. 1995), is unknown. Hence, it is possible that this second instructive signal is induced by a Rho-mediated transcriptional pathway, which is clearly distinct from the Rac-mediated transcriptional pathway. It is worth noting that our results do not exclude the possibility that the cell shape changes associated with the lateral epidermal cells require an additional direct (cell-autonomous) role for the Rhol-Pkn pathway in those cells as well. It is clear, however, that the role of Rhol in the LE cells during DC is distinct from that of Racl.

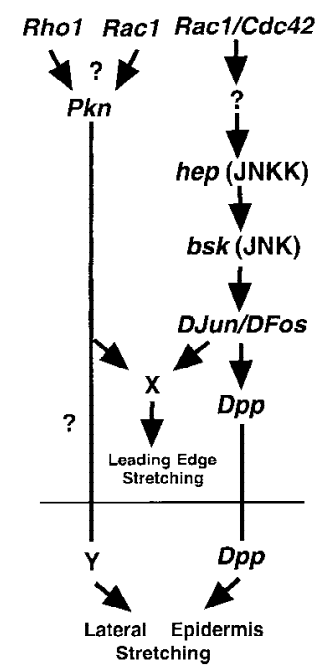

Figure 6. A model for the coordinated regulation of DC by distinct Rho family GTPases. The Rhol-Pkn pathway appears to function independently of the Rac-JNK-Dpp pathway, although Pkn might also transmit a Rac signal independent of the JNK-Dpp pathway. However, both Rho/Rac-Pkn and Rac-JNK pathways are required for signal $\mathrm{X}$, which is responsible for the stretching of LE cells along the dorsal-ventral axis. In addition, Rhol generates (possibly through $\mathrm{Pkn}$ ) an instructive signal $\mathrm{Y}$ in the LE cells, which, together with the Rac-JNK activation of $d p p$ expression in the LE cells, is required for stretching of all cells in the more lateral epidermis. The precise nature of the instructive signal $\mathrm{Y}$ is presently unknown, nor is it known whether signal $\mathrm{Y}$ is parallel to or downstream of the signal $\mathrm{X}$.

\section{Coordinated Rho and Rac activities are essential for $D C$}

In light of the fact that Drosophila Pkn interacts equally well with the activated Rac GTPase, it is possible that a Rac-Pkn interaction also contributes to DC. However, the lack of a Rac1 loss-of-function mutant in Drosophila makes it difficult to examine the specific role of that interaction. Because the JNK pathway mutants are also associated with a defect in stretching of the LE cells, it has been suggested that components of the JNK pathway may mediate a Rac-dependent cell stretching signal that is unrelated to transcriptional regulation (Fig. 6). It is difficult to imagine how Pkn could transduce a signal from Rac to this JNK-mediated cell shape change pathway and yet not be required for the Rac-JNK transcriptional pathway. However, it is possible that Pkn can transmit a Rac signal independent of the JNK-Dpp pathway. Indeed, we have found recently that the Drosophila gene Myoblast city, which is required for DC (Erickson et al. 1997), encodes a Rac-specific activator that does not appear to regulate $d p p$ expression (Nolan et al. 1998). This observation suggests that Rac may perform multiple functions in dorsal closure.

Significantly, there does seem to be some cross-talk between the Pkn-mediated signaling pathway and the JNK pathway. We observed, in a genetic interaction experiment, that removal of one copy of basket from a $P k n$ mutant GLC background significantly increases the fre- 
quency of dorsal-open embryos. This result suggests that some component of JNK cascade signaling is sensitive to the activity of Pkn. Taken together with the fact that Rhol generates a JNK-Dpp independent signal in the LE cells that is required for DC, it is clear from these studies that distinct but coordinated signaling pathways mediated by the Rho and Rac GTPases within the LE cells are essential for normal DC, and that Pkn is a strong candidate for an effector that mediates signals downstream of both GTPases.

\section{Materials and methods}

\section{Molecular cloning methods}

A genomic DNA fragment containing sequences encoding part of the kinase domain of a Drosophila homolog of mammalian PKN was isolated by PCR with a Drosophila genomic phage library and the following degenerate oligonucleotides: 5'GGNAG(G/C)GGNCA(A/T)TT/A/T)GGNAA/G/C)GT-3' and 5'-A/A/T)(A/T)TC(A/T)TC(A/T)TCNTCNTCNCC-3'. The PCR product was subcloned and used as a probe to screen a Drosophila eye imaginal disc cDNA library and an embryonic cDNA library. Several positive phage clones were purified. Their inserts were subcloned into pBluescript (Stratagene) and used to assemble a full-length $P k n$ cDNA, in which an in-frame stop codon was found $3 \mathrm{bp}$ upstream of the putative ATG start codon. The assembled cDNA was sequenced on both strands by use of the Sequenase kit (US Biochemicals) according to the manufacturer's instructions.

\section{Polytene chromosome in situ hybridization}

A Pkn probe labeled by digoxigenin (Genius kit 1; Boehringer Mannheim) was generated by PCR with the above-mentioned degenerate oligonucleotides and the subcloned $\mathrm{Pkn}$ genomic DNA according to manufacturer's recommendation. Chromosomal squashes were performed as described (Ashburner 1989), and in situ hybridization on polytene chromosomes was performed as described previously (Hariharan et al. 1995). Upon confirming the $45 \mathrm{C}$ map position of the Pkn locus, we found that a partial previously reported kinase sequence, designated $\mathrm{Pk} 45 \mathrm{C}$, is identical to Pkn (Kalderon and Rubin 1988).

\section{RNA in situ hybridization}

In situ mRNA hybridization was performed essentially as described (Van Vactor and Kopczynski 1998). In cases where a specific cross generated embryos of different genotypes, a lacZ RNA probe was also used to mark the embryos with the balancer chromosome that also contained a P-element insertion carrying the lac $Z$ gene. Sense probes were used as controls where appropriate.

\section{Immunohistochemistry}

Anti-fasciclin III (anti-Fas III) and other antibody stainings were performed as described (Patel 1994). The 7G10 anti-fas III monoclonal antibody has been reported previously (Patel et al. 1987) and was obtained from the Developmental Studies Hybridoma Bank maintained by The University of Iowa, Department of Biological Sciences, under contract NO1-HD-7-3263 from the NICHD. Similar results were obtained with the anti-coracle antibody kindly provided by Richard Fehon (Fehon et al. 1994). In cases where a specific cross generated embryos of different genotypes, an anti- $\beta$-galactosidase antibody (Promega) was also used to mark the embryos with the balancer chromosome that also contained a P-element insertion carrying the lacZ gene.

\section{GTPase binding and kinase assays}

A 3.6-kb cDNA encoding the full-length Drosophila Pkn protein was subcloned into the mammalian expression vector pCMV5-Flag such that Pkn with a Flag epitope at its amino terminus was expressed when transfected into BOSC cells by use of the standard calcium phosphate method. Cell extracts were prepared $48 \mathrm{hr}$ post-transfection in lysis buffer [50 $\mathrm{mm}$ HEPES (pH 7.4), $150 \mathrm{~mm} \mathrm{NaCl}, 1.5 \mathrm{~mm} \mathrm{MgCl}_{2}, 5 \mathrm{~mm}$ EGTA, $10 \%$ glycerol, $1 \%$ Triton X-100] and were precleared twice for $30 \mathrm{~min}$ at $4^{\circ} \mathrm{C}$ with protein $\mathrm{A}-$ Sepharose beads before use in binding assays. A similar strategy was used to express the isolated Flag-tagged Pkn HR1 domain and the Flag-tagged Pkn protein without the amino-terminal HR1 domains. Site-directed mutagenesis was used to generate the G58A point mutation in the Pkn cDNA according to the manufacturer's suggestion (QuickChange, Stratagene). The following pairs of oligonucleotides were used in the reaction: 5'-CTGAAGATCAAAGAGGCCGCCGAGAAGCTCCGC-3', and 5'-GCGGAGCTTCTCGGCGGCCTCTTTGATCTTCAG-3'. The G58A mutant Pkn with a Flag tag was expressed in BOSC cells as described above. Drosophila Rho1, Rac1, Rac2, and Cdc42 cDNAs were subcloned into pGEX20 vectors and GST fusion proteins were prepared according to standard methods. Equal amounts of GST fusion proteins and GST ( $\sim 30-60 \mu \mathrm{g} /$ assay) were incubated at $30^{\circ} \mathrm{C}$ for $30 \mathrm{~min}$ in $50 \mu \mathrm{l}$ of nucleotide exchange buffer $[50 \mathrm{~mm}$ HEPES (pH 7.08), 5 mM EDTA, 0.1 mM EGTA, 50 mm NaCl, 0.1 mM DTT] with $0.5 \mathrm{~mm}$ of GDP or GTP $\gamma \mathrm{S}$, and the reaction was terminated by addition of $\mathrm{MgCl}_{2}$ to a final concentration of 20 $\mathrm{mM}$. Then, precleared lysates were incubated with the GSTGTPases (GDP or GTP $\mathrm{S}$ bound) at $4^{\circ} \mathrm{C}$ for $1 \mathrm{hr}$ before the beads were washed three times in wash buffer [ 20 mM HEPES ( $\mathrm{pH} 7.5$ ), $150 \mathrm{~mm} \mathrm{NaCl}, 10 \%$ glycerol, $0.1 \%$ Triton X-100] and analyzed by SDS-PAGE, followed by immunoblotting with anti-Flag M2 monoclonal antibody (Sigma).

For kinase assays, Flag-Pkn captured either by GST-fusion proteins or M2 monoclonal antibody (immunoprecipitation) as described above was washed three times in wash buffer and once in kinase buffer [20 mM HEPES (pH 7.5), $100 \mathrm{~mm} \mathrm{NaCl}, 10$ $\mathrm{mM} \mathrm{MgCl}_{2}$ ] before assay. Half of each sample was subjected to immunoblotting to determine the relative amount of Flag-Pkn in each sample, while the other half was incubated at room temperature for $20 \mathrm{~min}$ in $25 \mu \mathrm{l}$ of kinase buffer containing 2 $\mu \mathrm{Ci}$ of $\left[\gamma^{-{ }^{32}} \mathrm{P}\right] \mathrm{ATP}(\mathrm{NEN})$. The autokinase reactions were terminated by washing three times in wash buffer and boiling in SDS-containing sample buffer. After SDS-PAGE analysis and autoradiography, bands corresponding to Pkn were cut from the dried gel, and radioactivity was determined in a scintillation counter. The normalized radioactivities of the bands were compared to calculate the degree of Pkn activation. To facilitate the determination of the amount of Flag-Pkn in each sample, twofold serial dilutions of the immunoprecipitated samples were compared with the amount of Flag-Pkn isolated by GSTGTPase capture.

\section{Cuticle preparations}

Overnight collections of embryos from various crosses were allowed to age at $25^{\circ} \mathrm{C}$ for $36 \mathrm{hr}$ before dechorionation in $50 \%$ bleach and devitellination. Cuticle preparations were carried out as described previously (Nüsslein-Volhard et al. 1984) 


\section{Germ-line transformations and heat shock rescue}

A full-length Pkn cDNA was subcloned into the pCaSpeR-hs vector, and transgenic flies harboring this cDNA construct $(P[h s-P k n])$ were generated according to standard procedures. A transgenic fly line carrying $P[h s-P k n]$ on the third chromosome was used to generate flies of the following genotype: $\mathrm{Pkn}^{P} / \mathrm{CyO}$; $P[h s-P k n]$. To test the heat-shock rescue of the lethality associated with the P-element insertion, the $\mathrm{F}_{1}$ progeny growing at $25^{\circ} \mathrm{C}$ were subjected to $30-\mathrm{min}$ heat shock at $37^{\circ} \mathrm{C}$ twice a day from 24 hr to 14 days after egg laying (AEL). Approximately 20\% of the mutants could be rescued to adulthood and were fertile. Similar results were obtained with a different transgenic fly line that had a second chromosomal insertion of the same $P$ [hs-Pkn] transgene.

\section{GLC analysis}

GLC mutants of Pkn were generated by a previously described method (Chou et al. 1993) using the $P \mathrm{kn}^{P}$ allele. Males of the genotype y $\mathrm{W} f \mathrm{flp} / \mathrm{Y} ; \mathrm{P}\left[\mathrm{mW}^{+} \text {; FRT42B }\right]^{\mathrm{G} 13} \mathrm{P}\left[\mathrm{mW}^{+} \text {; ovo }{ }^{D 1}\right]^{32 X 9}$ were mated to virgin females of the genotype $W ; P\left[\mathrm{~mW}^{+}\right.$, FRT42B $]^{G 13} \mathrm{Pkn}^{P}$ and heat shocked for $1 \mathrm{hr}$ at $37^{\circ} \mathrm{C}$ on days 4 , 5 , and 6 , to induce recombination. The female $F_{1}$ progeny with the genotype $W / y \quad W$ flp; $P\left[\mathrm{~mW}^{+} ; 42 B\right]^{G 13} \mathrm{P}\left[\mathrm{mW}^{+} ; \mathrm{OVO}^{D 1}\right] /$ $P\left[\mathrm{~mW}^{+} \text {.hs FRT42B }\right]^{G 13} \mathrm{Pkn}^{P}$ in which GLCs had been generated were then mated to males of the genotype $P \mathrm{kn}^{P} / \mathrm{CyO} w \mathrm{w}-1 \mathrm{acZ}$, $w / Y ; D f(2 R)$ w73-1, cn/CyO wg-lacZ (referred to as $D f(45 C)$ / $\mathrm{CyO}$ in text; stock number 80763A from the Umea Stock Center, Sweden), or $b s k^{1} \mathrm{Pkn}^{P} / \mathrm{CyO} w g-l a c Z$ (generated by recombining $b s k^{1}$ and $P \mathrm{kn}^{P}$ alleles) for phenotypic analysis.

\section{Genetics}

The fly stock that harbors a P-element insertion in the Pkn locus was obtained from the Bloomington Stock Center, with the stock description \#P2322 $P\{r y[+t 7.2]=P Z\} 1(2) 06736[06736]$ cn[1]/CyO; ry[506]. Rho1 mutant allele $R h o 1^{720}$ was from M. Mlodzik (EMBL, Heidelberg, Germany). The LE-GAL4 driver line was obtained from S. Noselli (Centre National de Recherché Scientifique, Toulouse, France). The UAS-Rho1 ${ }^{\text {N19 }}$ was provided by D. Montell (Johns Hopkins University, Baltimore, $\mathrm{MD})$. The basket ${ }^{1} / \mathrm{CyO}, \mathrm{Pkn}^{P} / \mathrm{CyO}$ and various other stocks were from the Bloomington and Umea Stock Centers. Precise excision of the P-element was carried out according to standard procedures. Briefly, P-element harboring flies of the genotype $\mathrm{Pkn}^{\mathrm{P}[\mathrm{ry}+]} / \mathrm{CyO} ; \mathrm{ry}^{506}$ were mated to transposase-containing flies of the genotype $C y O / S p ; S b, \Delta 2-3 / T M 6, U b x$. The male $F_{1}$ progeny of the genotype $\mathrm{Pkn}^{P[r y+]} / \mathrm{CyO} ; \mathrm{Sb}, \Delta 2-3 / \mathrm{ry}^{506}$ were selected, and each was mated individually with $\mathrm{CyO} / \mathrm{Sp} ; \mathrm{ry}^{506}$ virgin females. Approximately 160 such crosses were performed, and one to eight $\mathrm{F}_{2}$ male progeny of the genotype $P \mathrm{kn}^{E[P]} / \mathrm{CyO} ; \mathrm{ry}^{506}$ from each cross, which potentially harbored the excision allele of the original $\mathrm{P}$ allele, were mated individually with the original P-element harboring flies of the genotype $\mathrm{Pkn}^{P[r y+]} / \mathrm{CyO} ; \mathrm{ry}^{506}$. Only vials with $\mathrm{CyO}^{+}$flies of the genotype $P k n^{E[P]} / P k n^{P[r y+]}$ were retained, and stocks were established with the rosy-eyed $P \mathrm{kn}^{E[P]} / \mathrm{CyO} ; \mathrm{ry}^{506}$ progeny from the same cross.

To determine the percentage of embryos with DC defects, GLC virgin females were mated with males of the following genotypes, respectively: $P \mathrm{kn}^{P} / \mathrm{CyO} w g-1 a c Z, D f(45 C) / C y O$ wg-lacZ, $\mathrm{Pkn}^{P}$ bsk $/ \mathrm{CyO}$ wg-lacZ, $\mathrm{Pkn}^{P}$ Rho1 ${ }^{72 R} / \mathrm{CyO}$ wg- $^{-}$ $1 a c Z$, and $P \mathrm{kn}^{P} / \mathrm{CyO} w g-1 a c Z ; P[h s-P k n]$. In the case of zygotic mutants, $P \mathrm{kn}^{P[\mathrm{ml1}]} / \mathrm{CyO} w \mathrm{w}-\mathrm{lacZ}$ flies were used. Overnight collections of 0 - to 18 -hr embryos were obtained, and all em- bryos were allowed to develop $48 \mathrm{hr}$ more before progeny were dechorionated and counted. Alternatively, to count only mutants, overnight collections of embryos were stained for $\beta$-galactosidase to distinguish mutants from heterozygotes harboring a lacZ gene on the balancer chromosome. Embryos beyond stage 13 and of mutant genotypes were counted.

For anti- $\beta$-galactosidase staining of puckered-lac $Z$ enhancer trap in a $P k n G L C$ or hep ${ }^{1}$ mutant background, a double balanced stock of $P \mathrm{kn}^{P} / \mathrm{CyO}$; puc WG1173/TM3 ftz-lacZ was established and crossed to Pkn GLC virgins or hep ${ }^{1}$ virgins. The presence of the puckered-lacZ enhancer trap (puc ${ }^{\text {WG117) }}$ ) was indicated by the absence of the ftz-lacZ (TM3 balancer).

\section{Acknowledgments}

We thank Marek Mlodzik for the Rho1 mutant stocks, Stephane Noselli for the LE-GAL4 stock, Denise Montell for the UAS$R h o 1^{N 19}$ stock, Laurel Raftery for the puckered-lacZ enhancer trap line, Ernst Hafen for the $d p p$ cDNA clone, the Bloomington and Umea Stock Centers for the basket ${ }^{1} / \mathrm{CyO}, \mathrm{Pkn}^{P} / \mathrm{CyO}$ and various other stocks. We are also grateful to David Van Vactor, Liz Perkins, Laurel Raftery, Fangli Chen, and members of our laboratory for helpful suggestions, and Laurel Raftery, Iswar Hariharan, Katie Nolan, Sylvie Vincent, Rosemary Foster, and Kathy Barrett, for critical reading of the manuscript. This work was supported by an award to J.S. from the American Cancer Society.

The publication costs of this article were defrayed in part by payment of page charges. This article must therefore be hereby marked 'advertisement' in accordance with 18 USC section 1734 solely to indicate this fact.

\section{References}

Amano, M., H. Mukai, Y. Ono, K. Chihara, T. Matsui, Y. Hamajima, K. Okawa, A. Iwamatsu, and K. Kaibuchi. 1996. Identification of a putative target for Rho as the serine-threonine kinase protein kinase N. Science 271: 648-650.

Ashburner, M. 1989. Polytene chromosomes. In Drosophila: A laboratory handbook. (ed. M. Ashburner), pp. 33-38. Cold Spring Harbor Laboratory Press, Cold Spring Harbor, NY.

Barrett, K., M. Leptin, and J. Settleman. 1997. The Rho GTPase and a putative RhoGEF mediate a signaling pathway for the cell shape changes in Drosophila gastrulation. Cell 91: 905915.

Brand, A.H. and N. Perrimon. 1993. Targeted gene expression as a means of altering cell fates and generating dominant phenotypes. Development 118: 401-415.

Chou, T.B., E. Noll, and N. Perrimon. 1993. Autosomal P[ovoD1] dominant female-sterile insertions in Drosophila and their use in generating germ-line chimeras. Development 119: 1359-1369.

Coso, O.A., M. Chiariello, J.C. Yu, H. Teramoto, P. Crespo, N. $\mathrm{Xu}$, T. Miki, and J.S. Gutkind. 1995. The small GTP-binding proteins Rac1 and Cdc42 regulate the activity of the JNK/ SAPK signaling pathway. Cell 81: 1137-1146.

Cryns, V.L., Y. Byun, A. Rana, H. Mellor, K.D. Lustig, L. Ghanem, P.J. Parker, M.W. Kirschner, and J. Yuan. 1997. Specific proteolysis of the kinase protein kinase C-related kinase 2 by caspase- 3 during apoptosis. Identification by a novel, small pool expression cloning strategy. J. Biol. Chem. 272: 29449-29453.

Erickson, M.R., B.J. Galletta, and S.M. Abmayr. 1997. Drosophila myoblast city encodes a conserved protein that is 
essential for myoblast fusion, dorsal closure, and cytoskeletal organization. I. Cell Biol. 138: 589-603.

Fehon, R.G., I.A. Dawson, and S. Artavanis-Tsakonas. 1994. A Drosophila homologue of membrane-skeleton protein 4.1 is associated with septate junctions and is encoded by the coracle gene. Development 120: 545-557.

Flynn, P., H. Mellor, R. Palmer, G. Panayotou, and P.J. Parker. 1998. Multiple interactions of PRK1 with RhoA: Functional assignment of the HR1 repeat motif. J. Biol. Chem. 273: 2698-2705.

Glise, B., H. Bourbon, and S. Noselli. 1995. hemipterous encodes a novel Drosophila MAP Kinase Kinase, required for epithelial cell sheet movement. Cell 83: 451-461.

Glise, B. and S. Noselli. 1997. Coupling of Jun amino-terminal kinase and Decapentaplegic signaling pathways in Drosophila morphogenesis. Genes \& Dev. 11: 1738-1747.

Hacker, U. and N. Perrimon. 1998. DRhoGEF2 encodes a member of the Dbl family of oncogenes and controls cell shape changes during gastrulation in Drosophila. Genes \& Dev. 12: $274-284$.

Harden, N., H.Y. Loh, W. Chia, and L. Lim. 1995. A dominant inhibitory version of the small GTP-binding protein Rac disrupts cytoskeletal structures and inhibits developmental cell shape changes in Drosophila. Development 121: 903 914.

Hariharan, I.K., K.Q. Hu, H. Asha, A. Quintanilla, R.M. Ezzell, and J. Settleman. 1995. Characterization of rho GTPase homologues in Drosophila melanogaster: Overexpressing Rho1 causes a late developmental defect. EMBO J. 14: $292-$ 302.

Henning, S.W., R. Galandrini, A. Hall, and D.A. Cantrell. 1997. The GTPase Rho has a critical regulatory role in thymus development. EMBO I. 16: 2397-2407.

Hill, C.S., J. Wynne, and R. Treisman. 1995. The Rho family GTPases RhoA, Rac1, and $\mathrm{CDC} 42 \mathrm{Hs}$ regulate transcriptional activation by SRF. Cell 81: 1159-1170.

Hou, X.S., E.S. Goldstein, and N. Perrimon. 1997. Drosophila Jun relays the Jun amino-terminal kinase signal transduction pathway to the Decapentaplegic signal transduction pathway in regulating epithelial cell sheet movement. Genes \& Dev. 11: 1728-1737.

Kalderon, D. and G.M. Rubin. 1988. Isolation and characterization of Drosophila cAMP-dependent protein kinase genes. Genes \& Dev. 2: 1539-1556.

Kawamata, T., T. Taniguchi, H. Mukai, M. Kitagawa, T. Hashimoto, K. Maeda, Y. Ono, and C. Tanaka. 1998. A protein kinase, PKN, accumulates in Alzheimer neurofibrillary tangles and associated endoplasmic reticulum-derived vesicles and phosphorylates tau protein. I. Neurosci. 18: 7402-7410.

Kimura, K., M. Ito, M. Amano, K. Chihara, Y. Fukata, M. Nakafuku, B. Yamamori, J. Feng, T. Nakano, K. Okawa, A. Iwamatsu, and K. Kaibuchi. 1996. Regulation of myosin phosphatase by Rho and Rho-associated kinase (Rho-kinase). Science 273: 245-248.

Kitagawa, M., H. Shibata, M. Toshimori, H. Mukai, and Y. Ono. 1996. The role of the unique motifs in the amino-terminal region of PKN on its enzymatic activity. Biochem. Biophy. Res. Commun. 220: 963-968.

Kockel, L., J. Zeitlinger, L.M. Staszewski, M. Mlodzik, and D. Bohmann. 1997. Jun in Drosophila development: Redundant and nonredundant functions and regulation by two MAPK signal transduction pathways. Genes \& Dev. 11: 1748-1758.

Lamoureux, P., Z.F. Altun-Gultekin, C. Lin, J.A. Wagner, and S.R. Heidemann. 1997. Rac is required for growth cone function but not neurite assembly. J. Cell Sci. 110: 635-641.
Lores, P., L. Morin, R. Luna, and G. Gacon. 1997. Enhanced apoptosis in the thymus of transgenic mice expressing constitutively activated forms of human Rac2GTPase. Oncogene 15: 601-605.

Luo, L., L. Jan, and Y.N. Jan. 1996. Small GTPases in axon outgrowth. Perspect. Dev. Neurobiol. 4: 199-204.

Marais, R., Y. Light, H.F. Paterson, and C.J. Marshall. 1995. Ras recruits Raf- 1 to the plasma membrane for activation by tyrosine phosphorylation. EMBO J. 14: 3136-3145.

Martin-Blanco, E., A. Gampel, J. Ring, K. Virdee, N. Kirov, A.M Tolkovsky, and A. Martinez-Arias. 1998. puckered encodes a phosphatase that mediates a feedback loop regulating JNK activity during dorsal closure in Drosophila. Genes \& Dev. 12: $557-570$.

Martinez-Arias, A. 1993. Development and patterning of the larval epidermis of Drosophila. In The development of Drosophila melanogaster. Cold Spring Harbor Laboratory Press, Cold Spring Harbor, NY.

Minden, A., A. Lin, F.X. Claret, A. Abo, and M. Karin. 1995. Selective activation of the JNK signaling cascade and c-Jun transcriptional activity by the small GTPases Rac and Cdc42Hs. Cell 81: 1147-1157.

Mukai, H., K. Mori, H. Takanaga, M. Kitagawa, H. Shibata, M. Shimakawa, M. Miyahara, and Y. Ono. 1995. Xenopus PKN Cloning and sequencing of the cDNA and identification of conserved domains. Biochim. Biophys. Acta 1261: 296-300.

Mukai, H., M. Toshimori, H. Shibata, M. Kitagawa, M. Shimakawa, M. Miyahara, H. Sunakawa, and Y. Ono. 1996. PKN associates and phosphorylates the head-rod domain of neurofilament protein. J. Biol. Chem. 271: 9816-9822.

Murphy, A.M. and D.J. Montell. 1996. Cell type-specific roles for CDC42, Rac and RhoL in Drosophila oogenesis. J. Cell Biol. 133: 617-630.

Nobes, C.D. and A. Hall. 1995. Rho, Rac, and Cdc42 GTPases regulate the assembly of multimolecular focal complexes associated with actin stress fibers, lamellipodia, and filopodia. Cell 81: 53-62.

Nolan, K.M., K. Barrett, Y. Lu, K.Q. Hu, S. Vincent, and J. Settleman. 1998. Myoblast city, the Drosophila homolog of DOCK180/CED-5, is required in a rac signaling pathway utilized for multiple developmental processe. Genes \& Dev. 12: 3337-3342.

Noselli, S. 1998. JNK signaling and morphogenesis in Drosophila. Trends Genet. 14: 33-38.

Nüsslein-Volhard, C., E. Wieschaus, and H. Kluding. 1984. Mutations affecting the pattern of the larval cuticle in Drosophila melanogaster. I. Zygotic loci on the second chromosome. Roux's Arch. Dev. Biol. 193: 267-282.

Palmer, R.H., J. Ridden, and P.J. Parker. 1995. Cloning and expression patterns of two members of a novel protein-kinaseC-related kinase family. Eur. J. Biochem. 227: 344-351.

Patel, N.H. 1994. Imaging neuronal subsets and other cell types in whole-mount Drosophila embryos and larvae using antibody probes. In Drosophila melanogaster: Practical uses in cell and molecular biology. (ed. L.S.B. Goldstein and E.A. Fyrberg), Vol. 44, pp. 446-488. Academic Press, San Diego, CA.

Patel, N.H., P.M. Snow, and C.S. Goodman. 1987. Characterization and cloning of fasciclin III: A glycoprotein expressed on a subset of neurons and axon pathways in Drosophila. Cell 48: 975-988.

Quilliam, L.A., Q.T. Lambert, L.A. Mickelson-Young, J.K. Westwick, A.B. Sparks, B.K. Kay, N.A. Jenkins, D.J. Gilbert, N.G. Copeland, and C.J. Der. 1996. Isolation of a NCK-associated kinase, $\mathrm{PRK} 2$, an SH3-binding protein and potential effector of Rho protein signaling. J. Biol. Chem. 271: 28772 
28776.

Ridley, A.J. and A. Hall. 1992. The small GTP-binding protein rho regulates the assembly of focal adhesions and actin stress fibers in response to growth factors. Cell 70: 389-399.

Ridley, A.J., H.F. Paterson, C.L. Johnston, D. Diekmann, and A. Hall. 1992. The small GTP-binding protein rac regulates growth factor-induced membrane ruffling. Cell 70: 401-410.

Riesgo-Escovar, J.R. and E. Hafen. 1997a. Common and distinct roles of DFos and DJun during Drosophila development. Science 278: 669-672.

- 1997b. Drosophila Jun kinase regulates expression of decapentaplegic via the ETS-domain protein Aop and the AP-1 transcription factor DJun during dorsal closure. Genes \& Dev. 11: 1717-1727.

Riesgo-Escovar, J.R., M. Jenni, A. Fritz, and E. Hafen. 1996. The Drosophila Jun-N-terminal kinase is required for cell morphogenesis but not for DJun-dependent cell fate specification in the eye. Genes \& Dev. 10: 2759-2768.

Sahai, E., A.S. Alberts, and R. Treisman. 1998. RhoA effector mutants reveal distinct effector pathways for cytoskeletal reorganization, SRF activation and transformation. EMBO J. 17: 1350-1361.

Sluss, H.K., Z. Han, T. Barrett, R.J. Davis, and Y.T. Ip. 1996. A JNK signal transduction pathway that mediates morphogenesis and an immune response in Drosophila. Genes \& Dev. 10: $2745-2758$.

Stapleton, G., C.P. Nguyen, K.A. Lease, and M.B. Hille. 1998. Phosphorylation of protein kinase C-related kinase PRK2 during meiotic maturation of starfish oocytes. Dev. Biol. 193: $36-46$.

Strutt, D.I., U. Weber, and M. Mlodzik. 1997. The role of RhoA in tissue polarity and Frizzled signalling. Nature 387: 292295.

Takahashi, M., H. Mukai, M. Toshimori, M. Miyamoto, and Y. Ono. 1998. Proteolytic activation of PKN by caspase-3 or related protease during apoptosis. Proc. Natl. Acad. Sci. 95: 11566-11571.

Ueno, N., I. Oishi, S. Sugiyama, Y. Nishida, Y. Minami, and H. Yamamura. 1997. Identification of a novel Drosophila protein kinase highly homologous to protein kinase N (PKN). Biochem. Biophys. Res. Commun. 232: 126-129.

Van Aelst, L. and C. D'Souza-Shorey. 1997. Rho GTPases and signaling networks. Genes \& Dev. 11: 2295-2322.

Van Vactor, D. and C. Kopczynski. 1998. Anatomical techniques for analysis of nervous system development in the Drosophila embryo. In A Comparative Methods Approach to the Study of Oocytes and Embryos. (ed. J. Richter), Oxford University Press, New York. (in press).

Vincent, S. and J. Settleman. 1997. The PRK2 kinase is a potential effector target of both Rho and Rac GTPases and regulates actin cytoskeletal organization. Mol. Cell. Biol. 17: $2247-2256$.

Watanabe, G., Y. Saito, P. Madaule, T. Ischizaki, K. Fujisawa, N. Morii, H. Mukai, Y. Ono, S. Kakizuka, and S. Narumiya. 1996. Protein kinase N (PKN) and PKN-related protein rhophillin as targets of small GTPase Rho. Science 271: 645648.

Zeitlinger, J., L. Kockel, F.A. Peverali, D.B. Jackson, M. Mlodzik, and D. Bohmann. 1997. Defective dorsal closure and loss of epidermal decapentaplegic expression in Drosophila fos mutants. EMBO I. 16: 7393-7401.

Zipkin, I.D., R.M. Kindt, and C.J. Kenyon. 1997. Role of a new Rho family member in cell migration and axon guidance in C. elegans. Cell 90: 883-894. 


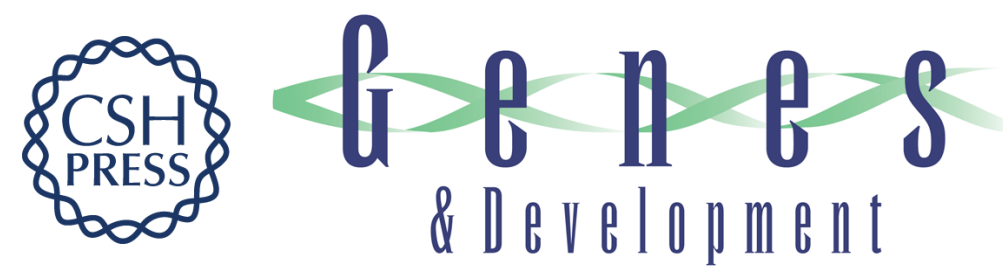

\section{The Drosophila Pkn protein kinase is a Rho/Rac effector target required for dorsal closure during embryogenesis}

Yu Lu and Jeffrey Settleman

Genes Dev. 1999, 13:

References This article cites 54 articles, 32 of which can be accessed free at: http://genesdev.cshlp.org/content/13/9/1168.full.html\#ref-list-1

License

Email Alerting

Service right corner of the article or click here.

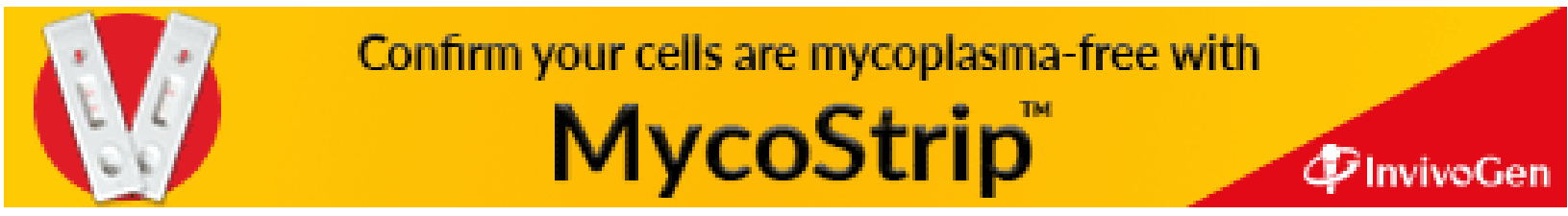

